\title{
Feasibility of bioelectrical impedance analysis in children with a severe generalized cerebral palsy
}

\author{
Rebekka Veugelers, M.Sc. ${ }^{\mathrm{a}, \mathrm{b}}$, Corine Penning, M.Sc., Ph.D. ${ }^{\mathrm{a}, \mathrm{b}, * \text {, }}$ \\ Michiel E. van Gulik, M.Sc. ${ }^{a}$, Dick Tibboel, M.D., Ph.D. ${ }^{\mathrm{b}}$, and \\ Heleen M. Evenhuis, M.D., Ph.D. ${ }^{a}$ \\ ${ }^{a}$ Intellectual Disability Medicine, Department of General Practice, Erasmus University Medical Center, Rotterdam, The Netherlands \\ ${ }^{\mathrm{b}}$ Department of Pediatric Surgery, Erasmus University Medical Center-Sophia, Rotterdam, The Netherlands
}

Manuscript received November 7, 2004; accepted May 3, 2005.

\begin{abstract}
Objective: The need is strong for an accurate and easy-to-perform test to evaluate the nutritional state of children who have a severe generalized cerebral palsy, defined as a severe motor handicap and an intellectual disability. For that purpose, we determined the feasibility of bioelectrical impedance analysis (BIA) in these children and evaluated their nutritional state.

Methods: BIA recordings were done in 35 children who had a severe generalized cerebral palsy using a single-frequency BIA device. In addition, arm span and body weight were determined. Components of feasibility were whether the children tolerated the recording and felt comfortable and whether the recording could be performed in a reproducible way (prescribed body position and stable resistance and reactance values). All recordings were performed at specialized children's daycare centers or schools.

Results: One child (3\%) did not tolerate the recording, whereas the remaining 34 children $(71 \%)$ felt comfortable. Most children (74\%) could be placed in the prescribed position, but stability of resistance values was low. Stability of resistance values was positively influenced by older age, a quiet location for the recording, feeling comfortable, and a small number of people in the room. For 29 children, we were able to calculate values for total body water and fat-free mass. Compared with age-matched reference values, these values were significantly decreased in all age groups.

Conclusions: The present pilot study has demonstrated that BIA recording is a feasible nutritional assessment method in children who have severe generalized cerebral palsy. Because the test procedure was well tolerated by most children, its value for use in this specific population deserves further investigation. (c) 2006 Elsevier Inc. All rights reserved.
\end{abstract}

\section{Introduction}

In children who have a severe generalized cerebral palsy (CP) and intellectual disability, comorbidity is high. The etiology of CP may differ considerably: some underlying disorders are chromosomal defects, cerebral hemorrhage, infantile encephalopathy, or metabolic disorders. In these children,

This study was financially supported by The Dutch Organization for Health Research and Development.

* Corresponding author. Tel.: +0031-10-463-2123; fax: +0031-10463-2127.

E-mail address: c.penning@erasmusmc.nl (C. Penning). feeding difficulties, such as gastroesophageal reflux and dysphagia, are frequently observed. The prevalence of gastroesophageal reflux, a disorder associated with vomiting and food refusal [1], varies from $61 \%$ to $96 \%$ [2-5], whereas dysphagia, a disorder of neurologic origin that limits food intake, has been observed in $19 \%$ to $38 \%$ [6,7] of these children. Other disorders limiting food intake are hypersensitivity of the oropharynx [8] and poor appetite [9], which might be enhanced by chronic constipation $[10,11]$. These feeding difficulties, in combination with an altered energy metabolism, might lead to problems with the nutritional state. The prevalence of malnutrition in these children is high: when comparing their results of nutritional assessment tests with reference val- 
ues for school children or values obtained from a control group of non-handicapped children, approximately $40 \%$ of children with severe generalized $\mathrm{CP}$ are undernourished [12-15]. Because malnutrition has a profound negative effect on health and quality of life, early diagnosis of malnutrition in these children is desirable.

Several methods are available for evaluation of the nutritional state. However, sophisticated methods such as the deuterium dilution technique or dual energy X-ray absorptiometry are not applicable for routine evaluation of the nutritional state because such methods are very expensive or available only in specialized hospitals. In addition, the value of methods that are commonly applied by pediatricians or outside the hospital, such as anthropometry, remains unclear and the results have to be interpreted with caution. Due to contractures and scoliosis, standing height often cannot be measured in a reliable way and therefore the use of alternative measures, such as lower leg length, has been recommended for this population [16]. In addition, most children with $\mathrm{CP}$ have growth retardation $[17,18]$, thus limiting the use of growth charts that include weight or height for age. Further, the value of skinfold measurements might be limited in these children due to a different distribution of subcutaneous fat $[19,20]$. As a result, professionals involved in the medical care for these children, such as intellectual disability physicians, pediatricians, pediatric surgeons, and dietitians, are in need of an easy-to-perform and accurate technique to monitor the nutritional state and evaluate the effect of surgical procedures such as gastrostomy or antireflux surgery.

Compared with the deuterium dilution technique, bioelectrical impedance analysis (BIA) is a valid $[21,22]$ method to determine the nutritional state in non-handicapped children. This inexpensive, quick, and non-invasive method determines aspects of body composition, such as fat-free mass and total body water, by measuring its reactance $(\mathrm{Xc})$ and resistance (Rz) [23]. In clinical practice, the determination of body composition is an accepted measurement for the investigation of growth in children and adolescents irrespective of their standing height and is an alternative for the use of growth charts [24]. The BIA equipment is portable and can easily be connected to the body. Further, BIA has low intra- and interobserver variabilities [25]. The value of BIA in children with severe generalized CP has not yet been investigated in detail; a previous study suggested that BIA is a useful technique in this population [26], but the number of children in that study was limited $(n=13)$ and feasibility data had not been recorded. During a BIA recording, patients should be in a supine position with their arms and legs abducted from the body. Because these children cannot be instructed and often have contractures of the limbs and some are very uncomfortable when lying on their backs, a study of the technical feasibility of BIA in these children would be useful.

Thus, the main objective of the present pilot study was to investigate the feasibility of BIA in a representative subset of children who had severe generalized $\mathrm{CP}$ and, if possible, to evaluate their nutritional state.

\section{Materials and methods}

\section{Subjects}

This study is a part of a large-scale epidemiologic study investigating the prevalence and risk factors of recurrent lower respiratory tract infections and malnutrition in 200 children who have severe generalized CP. Inclusion criteria for that study were a moderate to profound intellectual disability (intelligence quotient $<55$ ), a severe motor handicap (hyper- or hypotonic generalized CP or a severe motor developmental delay) corresponding to functional levels 4 or 5 on the Gross Motor Functional Classification Scale [27], and age between 2 and $18 \mathrm{y}$. There were no specific exclusion criteria. Verbal communication with these children is very limited due to their disabilities. To obtain a representative study population, children were not selected through hospitals. Instead, because $95 \%$ of these children visit a specialized children's daycare center or school, we selected the cohort through 54 participating daycare centers and schools in the western and middle part of the Netherlands. Informed consent was obtained from the parents of each child. The first 35 children for whom informed consent was obtained participated in the present feasibility pilot. This sample was a representative subset of the cohort because general characteristics such as mean age, sex, standing height, and weight were similar between these children and the total cohort (data not shown). The Dutch Central Committee on Research Involving Human Subjects approved the study protocol.

\section{Bioelectrical impedance analysis}

All BIA recordings [28] were performed once in each child at the daycare centers or schools. First, body temperature was recorded using an ear thermometer (IRT 3020, Braun GmbH, Kronberg, Germany) to exclude children with fever because fever influences the impedance of the body [29]. Second, we determined body weight and a measurement for standing height. Kyphosis and scoliosis are common in children with severe generalized CP [30] so we decided to measure arm span instead of standing height. While sitting, the child's arms were gently stretched and positioned so that the arms formed a $90^{\circ}$ angle to the trunk. Then the distance between the tips of both middle fingers was determined by using a flexible tape measure. Body weight was determined using a portable digital weight plateau (096200, Lopital Nederland B.V., Oisterwijk, The Netherlands) that was suitable for wheelchair placement.

While in the supine position, the child's shoes and socks and, if present, supportive calf or ankle braces were removed. According to the BIA manual, we aimed to keep the 
children in a resting supine position for $10 \mathrm{~min}$ before starting the recording. During that period, four electrodes (LecTec resting electrodes, LecTec Corporation, Minnetonka, MN, USA) were attached to the child's wrist and ankle on one side of the body and connected to a tetrapolar single-frequency BIA device with a three-digit display (STA/BIA Soft Tissue Analyzer, Akern Bioresearch, Florence, Italy) and a maximum measurable value for $\mathrm{Rz}$ of $999 \Omega$. The child was then gently put into the prescribed position, with arms and legs stretched and $30^{\circ}$ abducted from the trunk [31]. If necessary, the investigator fixed the limbs with a flannel blanket during the recording.

Components of feasibility were 1) whether the children tolerated the recording and felt comfortable, 2) accuracy and effects of the child's body position during the recording, and 3) stability of the Rz and Xc values.

The number of people in the room during the measurement and the location (classroom or separate room) were logged. Because these children are unable to communicate verbally, the investigator carefully observed the children during the recording for signs of emotional stress, such as protest behavior, fear, or crying, to estimate whether they felt comfortable. A child was supposedly uncomfortable if it showed signs of emotional stress, such as protest behavior, fear, or crying. To prevent interobserver variability of the subjective feasibility data, all children were observed by the same person. In addition, we recorded whether the children were in the correct position during the recording.

During the recording, the most stable values for $\mathrm{Rz}$ and $\mathrm{Xc}$ were logged. Because a previous study had reported fluctuating $\mathrm{Rz}$ and $\mathrm{Xc}$ values in this population [26], we measured the duration of stability of Rz and Xc values and subdivided them into 3 categories: stable for longer than $5 \mathrm{~s}$, 2 to $5 \mathrm{~s}$, or shorter than $2 \mathrm{~s}$. Because fluctuations of $\mathrm{Rz}$ and $\mathrm{Xc}$ influence the outcome of the recording, we considered this a relatively important aspect of feasibility.

Demographic factors and comorbidity (presence of spasticity and/or hypotonia, age, and sex) were logged from the medical records to determine their influence on feasibility.

\section{Analysis and statistics}

Arm span was converted to standing height according to the graph "arm span for standing height" for Dutch children
[32]. Body mass index (BMI) was calculated by dividing weight in kilograms by height in meters squared. Total body water (TBW) and fat-free mass (FFM) were calculated according to the cross-validated equations of Horlick et al. [33]:

$$
\begin{gathered}
\text { TBW }=0.725+0.475 \mathrm{H}^{2} / \mathrm{Rz}+0.140 \mathrm{~W} \\
\mathrm{FFM}=\left(3.474+0.459 \mathrm{H}^{2} / \mathrm{Rz}+0.064 \mathrm{~W}\right) /(0.769 \\
-0.009 \mathrm{~A}-0.016 \mathrm{~S})
\end{gathered}
$$

where $\mathrm{H}$ is standing height $(\mathrm{cm}), \mathrm{Rz}$ is resistance $(\Omega), \mathrm{W}$ is weight $(\mathrm{kg}), \mathrm{A}$ is age (y), and $\mathrm{S}$ is sex ( 1 for male, 0 for female). Children were subdivided into age groups of 4 to $8 \mathrm{y}(n=16), 9$ to $12 \mathrm{y}(n=12), 13$ to $15 \mathrm{y}(n=3)$, and 16 to $18 \mathrm{y}(n=3)$, so that group means of TBW and FFM could be statistically compared with age-matched reference values obtained from non-handicapped American children [33] using Student's unpaired $t$ test.

In addition, we calculated percentage of body fat that contributed to body weight according to the following formula:

$$
\text { body fat }(\%)=([\text { weight }- \text { FFM }] / \text { weight }) \times 100
$$

Feasibility parameters were statistically compared across children by using Pearson's chi-square test or Student's unpaired $t$ test, where appropriate. The influence of age on feasibility and the relation between BMI and body fat percentage were determined using linear regression analysis. Results are expressed as mean \pm standard deviation. $P<0.05$ was considered statistically significant.

\section{Results}

Clinical characteristics of the children are listed in Table 1.

\section{Feasibility}

None of the children had a body temperature higher than $38^{\circ} \mathrm{C}$. Due to motor activity, 11 children $(31 \%)$ were unable to maintain a supine resting position for at least $10 \mathrm{~min}$ preceding the BIA recording. We aimed to keep these children as long as possible in the supine position before start-

\begin{tabular}{|c|c|c|c|c|c|}
\hline \multicolumn{2}{|l|}{ General } & \multicolumn{2}{|l|}{ Etiology } & \multicolumn{2}{|l|}{ Motor handicap } \\
\hline Total number & 35 & Syndromes & $10(29 \%)$ & Hypertonia & $11(31 \%)$ \\
\hline Mean age $(y)$ & $8.7 \pm 4.0$ & Brain anomalies & $4(11 \%)$ & Hypertonia + hypotonia & $8(23 \%)$ \\
\hline Male/female & $19 / 16$ & Perinatal problems & $12(34 \%)$ & Hypotonia & $(34 \%)$ \\
\hline Mean height $(\mathrm{cm})$ & $127 \pm 20$ & Metabolic diseases & $5(14 \%)$ & Unknown & $4(12 \%)$ \\
\hline Mean weight (kg) & $26 \pm 10$ & Meningitis & $1(3 \%)$ & & \\
\hline Mean BMI $\left(\mathrm{kg} / \mathrm{m}^{2}\right)$ & $16.2 \pm 3.1$ & Unknown & $3(9 \%)$ & & \\
\hline
\end{tabular}
ing the BIA recording. After the rest period, the children

Table 1

Clinical characteristics

BMI, body mass index

Data are presented as mean \pm standard deviation. The percentage of children is presented within parentheses. 
were gently put into the prescribed position. Due to protest behavior during positioning, recording in one child was aborted. Nine of the 34 remaining children (26\%) were in an incorrect position during the recording due to one or more contractures of the limbs. In these children, the limbs were gently stretched as far as possible.

We observed considerable fluctuation in $\mathrm{Rz}$ and $\mathrm{Xc}$ values: in 16 of $34(47 \%)$ children values were stable for shorter than $2 \mathrm{~s}$, in 8 of $34(24 \%)$ values were stable from 2 to $5 \mathrm{~s}$, and in 10 of 34 (29\%) values were stable for longer than $5 \mathrm{sec}$. Rz showed significantly less fluctuation if the recording was performed in a room other than the classroom: in $73 \%$ of the recordings performed in the classroom, $\mathrm{Rz}$ values were stable for shorter than $2 \mathrm{~s}$ compared with $37 \%$ of the recordings performed in another room $(P=$ $0.017)$. In addition, $\mathrm{Rz}$ was stable significantly $(P<0.05)$ longer in older children and during recordings with a smaller number of people in the room (Table 2). However, no significant association was observed between duration of stability of $\mathrm{Rz}$ values and body position during the recording and duration of the rest period (data not shown). We observed that 24 of 34 children $(71 \%)$ felt comfortable during the recording, six children felt clearly uncomfortable, and comfort level in four children was unclear. All children who felt uncomfortable had unstable $\mathrm{Rz}$ values (stable $<2 \mathrm{~s}$ ), and stability of Rz was significantly $(P<$ 0.05 ) higher in children who felt comfortable (Table 2). Feeling comfortable was not associated with duration of the rest period, location of the recording, number of people in the room, the child's position, or other parameters (data not shown).

\section{Bioelectrical impedance analysis}

Results of 5 of the 34 completed BIA recordings were not interpretable because $\mathrm{Rz}$ reached a stable value of 999 $\Omega$. Because this is the highest value that can be recorded with a three-digit BIA device, it is unknown whether the true $\mathrm{Rz}$ value was $999 \Omega$ or higher. No association between an $\mathrm{Rz}$ value of $999 \Omega$ and body position during recording,

Table 2

Parameters influencing stability of Rz values

\begin{tabular}{llll}
\hline & \multicolumn{3}{l}{ Duration of Rz stability } \\
\cline { 2 - 4 } & $<2 \mathrm{~s}$ & $2-5 \mathrm{~s}$ & $>5 \mathrm{~s}$ \\
\hline $\begin{array}{l}\text { Mean age }(\mathrm{y})^{*} \\
\begin{array}{l}\text { No. of people in } \\
\text { room* }\end{array}\end{array}$ & $6.8 \pm 2.7(16)$ & $9.5 \pm 4.5(8)^{\ddagger}$ & $10.4 \pm 3.8(10)^{\ddagger}$ \\
$\begin{array}{l}\text { No. of children } \\
\text { who feel }\end{array}$ & $4 / 14(29 \%)$ & $0 / 6(0 \%)^{\ddagger}$ & $0 / 8(0 \%)^{\ddagger}$ \\
$\quad$ uncomfortable & & & \\
\hline
\end{tabular}

Rz, resistance

* The number of children per category is presented within parentheses.

${ }^{\dagger}$ Percentage of children is presented within parentheses.

${ }^{\ddagger} P<0.05$ versus $<2$ s.

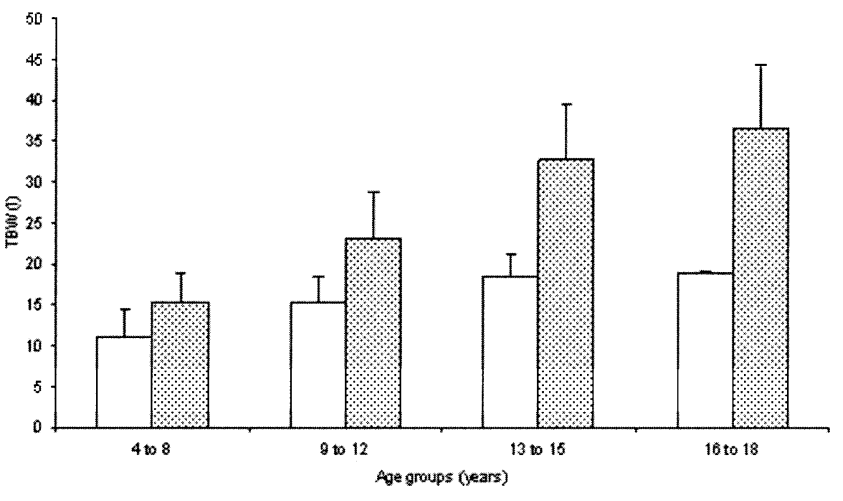

Fig. 1. Total body water (TBW) (mean \pm standard deviation) in different age groups of children with severe generalized cerebral palsy (open bars) and non-handicapped children (shaded bars).

demographic factors, or comorbidity was observed (data not shown).

Therefore, data from 29 of 35 recordings (83\%) could be used for calculation of TBW and FFM. Mean values for TBW and FFM were $13.4 \pm 0.81$ and $20.6 \pm 1.1 \mathrm{~kg}$, respectively. Figures 1 and 2 display mean values of TBW and FFM, respectively, by age group. In all age groups, mean TBW and FFM were lower in children who had severe generalized CP than in age-matched nonhandicapped controls from the literature [33]. These differences were statistically significant in children 4 to $8 \mathrm{y}$ and 9 to 12 y ( $P<0.000$ for both groups). Due to small numbers of children in the older groups, statistical comparisons were not possible.

The correlation between BMI and percentage of body fat is displayed in Fig. 3. In four children, fat mass had a negative value. In Fig. 3, these children are indicated by a body fat percentage of $0 \%$. A significant correlation $(r=$ 0.776, $P<0.05)$ between BMI and fat percentage was observed.

\section{Discussion}

Among specialists involved in health care for children with severe generalized $\mathrm{CP}$, the need for an accurate, easy-to-perform method for monitoring the nutritional state is strong. For that purpose, we have evaluated whether BIA might be a feasible method in these children. The present study has demonstrated that the feasibility of BIA in children with severe generalized CP is good. Most children (34 of 35) completed the recording and most children $(71 \%)$ felt comfortable during the recordings. However, we observed considerable fluctuation of $\mathrm{Rz}$ and $\mathrm{Xc}$ values. The most stable $\mathrm{Rz}$ values were obtained in older children and children who felt comfortable during the recording, during recordings in a quiet place, and with a smaller number of people in the room. Although $26 \%$ of children were not in the prescribed 
body position during the recording, this did not influence the stability of the recorded values. We demonstrated that, for all age groups, FFM and TBW were significantly lower in these children than in non-handicapped controls. In addition, a significant correlation was observed between body fat percentage and BMI.

Although we were able to calculate values for FFM and TBW in $83 \%$ of the participating children, we have to take into account that several aspects of the present test conditions might have had a negative influence on the reliability of these values. For example, food intake before the recording might have influenced the recorded values of $\mathrm{Rz}$ and $\mathrm{Xc}$ $[34,35]$. However, for logistical purposes, it was not possible in the present study to keep the children in the fasting state. Therefore, for future studies, it is recommended to record the time of meal intake or, if possible, to perform the recordings under fasting conditions. In addition, a correct body position for BIA recordings was not obtained in $26 \%$ of the children due to contractures of the limbs. However, the influence of an incorrect position on the outcome of the recording seems to be less pronounced because a previous study in these children has reported a good correlation between BIA and the deuterium dilution technique regardless of the presence of fixed contractures [26]. In that study, interpretation of BIA recordings in children who had generalized CP was severely limited by the children's continuous motor activity and involuntary movements. As a result, fluctuation of $\mathrm{Rz}$ and $\mathrm{Xc}$ values was prominent, resulting in a high coefficient of variation in these children [26]. This was confirmed by the findings of the present study because $\mathrm{Rz}$ values for stable longer than $5 \mathrm{~s}$ in only $29 \%$ of children. $\mathrm{Rz}$ values were most stable in older children and in those who felt comfortable. To increase stability of these values, performing the test in a quiet room with a small number of people in the room should be considered. Due to the lack of a validated prediction equation for this specific population, it is not yet possible to determine the clinical implications of fluctuating Rz and Xc values. However, it has been reported that the reproducibility of BIA recordings can be augmented

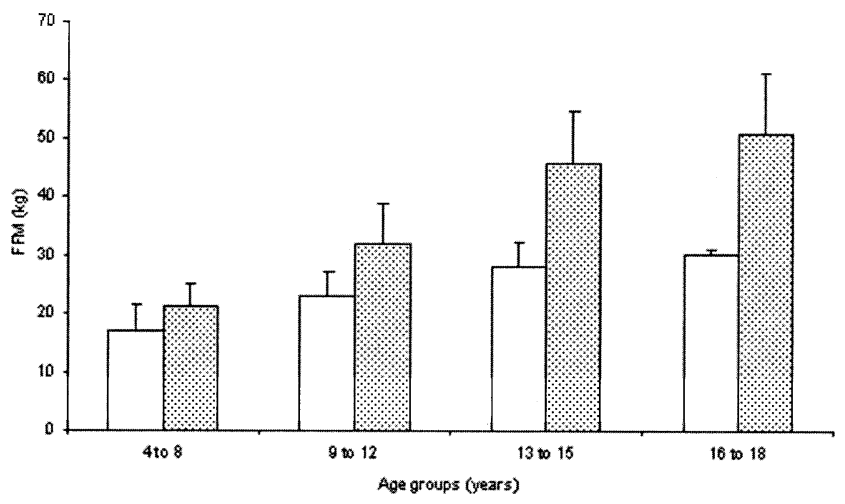

Fig. 2. Fat-free mass (FFM) (mean \pm standard deviation) in different age groups of children with severe generalized cerebral palsy (open bars) and non-handicapped children (dotted bars).

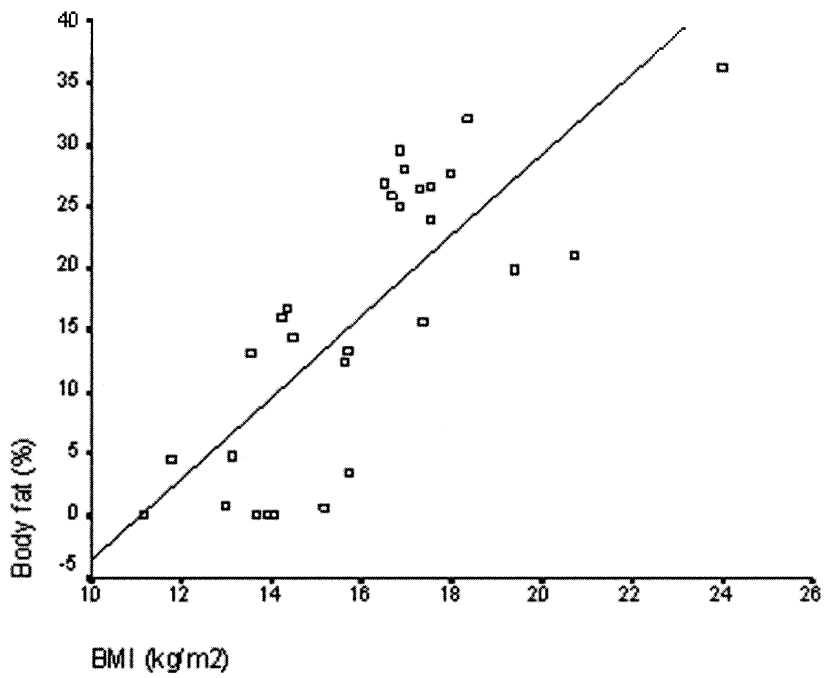

Fig. 3. Significant correlation $(r=0.776, P<0.05)$ between BMI and calculated body fat percentage according to the bioelectrical impedance analysis results in 29 children who had severe generalized cerebral palsy. BMI, body mass index.

by performing repeated measurements of $\mathrm{Rz}$ and $\mathrm{Xc}$ during a period of $10 \mathrm{~min}$ [36-38]. Therefore we advise measuring $\mathrm{Rz}$ and $\mathrm{Xc}$ at least three times to decrease the negative influence of unstable values in this population. In addition, we recommend the use of a four-digit BIA device for this group because $\mathrm{Rz}$ reached a stable value of $999 \Omega$ in $12 \%$ of recordings. Thus, with the present equipment it was uncertain whether $\mathrm{Rz}$ had a real value of $999 \Omega$ or higher. Increased $\mathrm{Rz}$ values have also been observed in patients with myotonic dystrophy [39], in dehydrated patients, and in patients with decreased lean body mass [40]. The clinical significance of the high $\mathrm{Rz}$ values in children with generalized $\mathrm{CP}$ has to be investigated in more detail. Because we demonstrated that a supine period shorter than $10 \mathrm{~min}$ as recommended by the manual did not influence the outcome of the recordings, this rest period might be omitted in future studies because the prescribed supine period is uncomfortable for some of these children. The additional value of the supine resting period before the recording has also been questioned by others [41].

Thus, BIA recordings in children with generalized $\mathrm{CP}$ should be performed in a quiet place with a small number of people in the room, and efforts should be made to make the child feel comfortable. In addition, performing the recording under fasting conditions is preferable. Further, we recommend repeated measurements of $\mathrm{Rz}$ and $\mathrm{Xc}$ and the use of a four-digit device.

We are well aware that a feasibility study is only the first step in the evaluation process of the applicability of BIA in this handicapped population. To determine the nutritional status of children with generalized CP using BIA, several additional aspects, apart from test validity, have to be determined. It is well known that the growth pattern of children with generalized CP is often disturbed [42]; in com- 
bination with long-term immobility, this might be the cause of a different body composition. A previous study has reported an increased internal fat deposit and a different distribution of subcutaneous fat in these children [20]. In addition, resting energy expenditure seems to be decreased $[26,43]$. As a consequence, the available prediction equations [44] and reference values for non-handicapped children may not apply to this special group. This is illustrated by the finding of negative values of percentage of body fat in four children. The present study has demonstrated lower values for TBW and FFM in children with generalized CP compared with non-handicapped children, but there is no clinical implication to this finding because these values might even be normal for these children. First, objective criteria for malnutrition in these children have to be established by performing a large-scale comparative study of several methods for nutritional assessment, including the deuterium dilution technique [45]. When comparing the outcome of the BIA recordings with those of the deuterium dilution technique, a specific, validated BIA prediction equation may be developed for these children. Second, test reproducibility should be evaluated with the help of precision studies to determine whether BIA in this population can be used at the individual or group level. Because the BIA recording was well tolerated by most of the studied children, further research into its clinical value in this special group is justified.

\section{Summary}

Bioelectrical impedance analysis is a feasible method for evaluation of the nutritional state in children with severe generalized cerebral palsy. Fat-free mass was decreased in the studied children. After optimization of the test procedure, its reproducibility and validity for this specific population should be determined.

\section{Acknowledgments}

The authors kindly acknowledge and thank Prof. Dr. H. N. Lafeber and Dr. A. M. W. J, Schols for helpful advice with regard to the interpretation of the results, research nurse Annelies A. Bos and medical student Stefan P. J. Grootscholten for assistance with the BIA recordings, and all participating children's daycare centers and special schools for their hospitality and cooperation.

\section{References}

[1] Field D, Garland M, Williams K. Correlates of specific childhood feeding problems. J Paediatr Child Health 2003;39:299-304.

[2] Böhmer CJ, Niezen-de Boer MC, , Klinkenberg-Knole EC, Deville WL, Nadorp JH, Meuwissen SG. The prevalence of gastroesophageal reflux disease in institutionalized intellectually disabled individuals. Am J Gastroenterol 1999;94:804-10.

[3] Gustafsson PM, Tibbling L. Gastro-oesophageal reflux and oesophageal dysfunction in children and adolescents with brain damage. Acta Paediatr 1994;83:1081-5.

[4] Reyes AL, Cash AJ, Green SH, Booth IW. Gastro-oesophageal reflux in children with cerebral palsy. Child Care Health Dev 1993;19:109-18.

[5] Gangil A, Patwari AK, Bajaj P, Kashyap R, Anand VK. Gastroesophageal reflux disease in children with cerebral palsy. Indian Pediatr 2001;38:766-70.

[6] Waterman ET, Koltai PJ, Downey JC, Cacace AT. Swallowing disorders in a population of children with cerebral palsy. Int J Pediatr Otorhinolaryngol 1992;24:63-71.

[7] Reilly S, Skuse D, Poblete X. Prevalence of feeding problems and oral motor dysfunction in children with cerebral palsy: a community survey. J Pediatr 1996;129:877-82.

[8] Reid JA, King PL, Kilpatrick NM. Desensitization of the gag reflex in an adult with cerebral palsy: a case report. Spec Care Dentist 2000;20:56-60.

[9] Thommessen M, Heiberg A, Kase BF, Larsen S, Riis G. Feeding problems, height and weight in different groups of disabled children. Acta Paediatr Scand 1991;80:527-33.

[10] Böhmer CJM, Taminiau JA, Klinkenberg-Knol EC, Meuwissen SG. The prevalence of constipation in institutionalized people with intellectual disability. J Intellect Disabil Res 2001;45:212-8.

[11] Sullivan PB. Gastrointestinal problems in the neurologically impaired child. Baillieres Clin Gastroenterol 1997;11:529-46.

[12] Sanchez-Lastres J, Eiris-Punal J, Otero-Cepeda JL, Pavon-Belinchon $\mathrm{P}$, Castro-Gago M. Nutritional status of mentally retarded children in north-west Spain. I. Anthropometric indicators. Acta Paediatr 2003; 92:747-53.

[13] Sanchez-Lastres J, Eiris-Punal J, Otero-Cepeda JL, Pavon-Belinchon $\mathrm{P}$, Castro-Gago M. Nutritional status of mentally retarded children in northwest spain: II. Biochemical indicators. Acta Paediatr 2003;92: 928-34.

[14] Sullivan PB, Lambert B, Rose M, Ford-Evans M, Johnson A, Griffiths P. Prevalence and severity of feeding and nutritional problems in children with neurological impairment: Oxford Feeding Study. Dev Med Child Neurol 2000;42:674-80.

[15] Dahl M, Thommessen M, Rasmussen M, Selberg T. Feeding and nutritional characteristics in children with moderate or severe cerebral palsy. Acta Paediatr 1996;85:697-701.

[16] Spender QW, Cronk CE, Charney EB, Stallings VA. Assessment of linear growth of children with cerebral palsy: use of alternative measures to height or length. Dev Med Child Neurol 1989;31:206-14.

[17] Samson-Fang L, Stevenson RD. Linear growth velocity in children with cerebral palsy. Dev Med Child Neurol 1998;40:689-92.

[18] Stevenson RD, Hayes RP, Cater LV, Blackman JA. Clinical correlates of linear growth in children with cerebral palsy. Dev Med Child Neurol 1994;36:135-42.

[19] Spender QW, Cronk CE, Stallings VA, Hediger ML. Fat distribution in children with cerebral palsy. Ann Hum Biol 1988;15:191-6.

[20] Berg-Emons RJvd, Baak MAv, Westerterp KR. Are skinfold measurements suitable to compare body fat between children with spastic cerebral palsy and healthy controls? Dev Med Child Neurol 1998;40: 335-9.

[21] Leman CR, Adeyemo AA, Schoeller DA, Cooper RS, Luke A. Body composition of children in south-western Nigeria: validation of bioelectrical impedance analysis. Ann Trop Paediatr 2003;23:61-7.

[22] Wabitsch M, Braun U, Heinze E, Muche E, Mayer H, Teller W, et al. Body composition in 5-18-y-old obese children and adolescents before and after weight reduction as assessed by deuterium dilution and bioelectrical impedance analysis. Am J Clin Nutr 1996;64:1-6.

[23] Kyle UG, Piccoli A, Pichard C. Body composition measurements: interpretation finally made easy for clinical use. Curr Opin Clin Nutr Metab Care 2003;6:387-93. 
[24] Sakate T. Relationship between body composition of school children and their growth. Ann Physiol Anthropol 1984;3:142-3.

[25] Gregory JW, Greene SA, Scrimgeour CM, Rennie MJ. Body water measurement in growth disorders: a comparison of bioelectrical impedance and skinfold thickness techniques with isotope dilution. Arch Dis Child 1991;66:220-2.

[26] Azcue MP, Zello GA, Levy LD, Pencharz PB. Energy expenditure and body composition in children with spastic quadriplegic cerebral palsy. J Pediatr 1996;129:870-6.

[27] Palisano R, Rosenbaum P, Walter S, Russell D, Wood E, Galuppi B. Development and reliability of a system to classify gross motor function in children with cerebral palsy. Dev Med Child Neurol 1997;39:214-23.

[28] Bioelectrical impedance analysis in body composition measurement. NIH Technology Assessment Statement 1994 December 12-14; 1-35. Nutrition 1996;12:749-62.

[29] Di Iorio BR, Terracciano V, Bellizzi V. Bioelectrical impedance measurement: errors and artifacts. J Ren Nutr 1999;9:192-7.

[30] Saito N, Ebara S, Ohotsuka K, Kumeta H, Takaoka K. Natural history of scoliosis in spastic cerebral palsy. Lancet 1998;351:1687-92.

[31] Nakadomo F, Watanabe K, Nakajima T, Shinya H, Tanaka K. Factors affecting the measurement of bioelectrical impedance-with special reference to limb position. Bull Osaka Pref Coll Nurs 1993;15:9-13.

[32] Gerver WJM, de Bruin R. Paediatric morphometrics. Utrecht: Wetenschappelijke Uitgeverij Bunge; 1996.

[33] Horlick M, Arpadi SM, Bethel J, Normand S, Laville M, Delawari E. Bioelectrical impedance analysis models for prediction of total body water and fat-free mass in healthy and HIV-infected children and adolescents. Am J Clin Nutr 2002;76:991-9.

[34] Gallagher M, Walker KZ, O'Dea K. The influence of a breakfast meal on the assessment of body composition using bioelectrical impedance. Eur J Clin Nutr 1998;52:94-7.
[35] Gualdi-Russo E, Toselli S. Influence of various factors on the measurement of multifrequency bioimpedance. Homo 2002;53:1-16.

[36] Lukaski HC, Johnson PE, Bolonchuk WW, Lykken GI. Assessment of fat-free mass using bioelectrical impedance measurements of the human body. Am J Clin Nutr 1985;41:810-7.

[37] Deurenberg P, Weststrate JA, Paymans I, van der Kooy K. Factors affecting bioelectrical impedance measurements in humans. Eur J Clin Nutr 1988;42:1017-22.

[38] Kushner RF, Schoeller DA. Estimation of total body water by bioelectrical impedance analysis. Am J Clin Nutr 1986;44:417-24.

[39] Johansson A, Andrew R, Forsberg H, Kederquist K, Walker BR, Olsson T. Glucocorticoid metabolism and adrenocortical reactivity to ACTH in myotonic dystrophy. J Clin Endocrinol Metab 2001;86: 4276-83.

[40] Arkouche W, Fouque D, Pachiaudi C, Wang J, Moye J Jr, Guff P, et al. Total body water and body composition in chronic peritoneal dialysis patients. J Am Soc Nephrol 1997;8:1906-14.

[41] Demura S, Yamaji S, Goshi F, Nagasawa Y. The influence of posture change on measurements of relative body fat in the bioimpedance analysis method. J Physiol Anthropol Appl Hum Sci 2001;20:29-35.

[42] Krick J, Murphy-Miller P, Zeger S, Wright E. Pattern of growth in children with cerebral palsy. J Am Diet Assoc 1996;96:680-5.

[43] Stallings VA, Zemel BS, Davies JC, Cronk CE, Charney EB. Energy expenditure of children and adolescents with severe disabilities: a cerebral palsy model. Am J Clin Nutr 1996;64:627-34.

[44] Kyle UG, Bosaeus I, De Lorenzo AD, Deurenberg P, Elia M, Gomez JM, et al. Bioelectrical impedance analysis-part I: review of principles and methods. Clin Nutr 2004;23:1226-43.

[45] Hills AP, Leyell L, Byrne NM. An evaluation of the methodology for the assessment of body composition in children and adolescents. Med Sport Sci 2001;44:1-13. 